\title{
JUVENTUDE INDÍGENA: ENCONTRO DA JUVENTUDE TERENA
}

\author{
Anderson de Souza Santos ${ }^{1}$ \\ Daniele Lorenço Gonçalves²
}

\begin{abstract}
RESUMO: O trabalho apresenta o processo de mobilização social da juventude Terena durante o IV Encontro da Juventude Terena para construir uma articulação entre jovens Terena de diferentes aldeias e municípios do Mato Grosso do Sul, com vistas a fortalecer e contribuir com o Movimento Indígena e o protagonismo juvenil. Através da observação participante e de diálogos com jovens Terena analisamos as formas que estão sendo desenvolvidos instrumentos de interação, diálogo e ligação da juventude indígena para que suas reinvindicações sejam ouvidas, assim como as trocas de experiências, em prol dos direitos dos povos indígenas. São manifestações ainda recentes, que oferecem novas e possíveis formas de vivenciar e interpretar a situação que se encontra, hoje, os povos indígenas do Estado.
\end{abstract}

Palavras-chave: Movimento Indígena. Encontro da Juventude. Povo Terena.

Mombyky: Ko tembiapo ohechauka ñemongu'e aty mitã guasu terena jejotopa guasu irundype, omopu'ã haḡua mbarete guasu mitã guasu terena ambue tekoha rupi Tetã Mato Grosso do Sul pe, upecha omopu'ã ha ombojoja mbarete Ava Ñemongu'e ndive. Ñemongueta rupi ñemaña kuaa hendive reheve ha ñemongueta mitã guasu Terena ndive, romaña mba'echapa hina ojapo hembiapo kuera oñondive meme oime hagua, upecha ojeporeka hemikoteve kueráre. Heta jehecha rupi ikatu jahecha ava reko ko Estadope, ikatu ave jahecha mba'echapa oñembyaty imi hikuai imbareteve haḡua.

Ñe'ẽ yta kuéra: Ava ñemongu'e. Jejotopa Mitã Guasu. Ava Terena.

RESUMEN: El trabajo presenta el proceso de movilización social de la juventud Terena durante el V Encuentro de la Juventud Terena para laconstituición de una articulación entre jóvenes Terena de diferentes aldeas y municipios de Mato Grosso do Sul con vistas a fortalecer y contribuir con el Movimiento Indígena y el protagonismo de la juventud. Através

\footnotetext{
1 Advogado, assessor jurídico do Conselho Terena. Endereço eletrônico: adv.andersonsantos@gmail.com.

2 Terena, docente de Língua Portuguesa da SED (Secretaria Estadual de Educação). Licenciada em Letras/Literatura (UNIGRAN) e Ciências Sociais (UFGD). Especialista em Culturas e Histórias dos Povos Indígenas pela UFMS e mestranda do Programa de Pós Graduação em Antropologia da UFGD. Endereço eletrônico: danilorenco@ hotmail.com.
} 
de la observación, diálogo y conexión de la juventud indígena para que sus reinvindicaciones sean escuchadas, así como los intercambios de experiencias, en pro de los derechos delos pueblos indígenas. Son manifestaciones aún recientes, que ofrecen nuevas y posibles formas de vivenciar e interpretar la situación que se encuentra hoy, los pueblos indígenas del Estado.

Palavras Clave: Movimiento Indígena. Encuentro de la Juventud. Pueblo Terena.

ABSTRACT: The work presents the social mobilization process of the Terena youth during the IV Terena Youth Meeting of building a link between Terena youngsters from different villages and cities from Mato Grosso do Sul, with the aim of strengthening and contributing to the Indigenous Movement and youth protagonism. Through the participant observation and dialogues with Terena youngsters, we analyze the ways in which instruments of interaction, dialogue and connection are being built so that their demands may be heard, as well as experiences exchanges, in favor to the rights of indigenous peoples. These are still recent manifestations, which offer new and possible ways of experiencing and interpreting the situation that are, nowadays, the indigenous peoples of this State.

Keywords: Indigenous. Movement. Meeting of the Youth. Terena People.

\section{Introdução}

O presente trabalho foi escrito por uma professora Terena e um assessor jurídico do Conselho Terena. No ano de 2017, firmamos uma parceria para dar suporte ao Conselho da Juventude Terena, na realização do V Encontro da Juventude Terena, ocorrido nos dias 18, 19, 20 e 21 de outubro de 2017, na aldeia Cabeceira, T.I. Nioaque, município de Nioaque, Mato Grosso do Sul.

Em 2015 participei, a convite da Edna Marques, vice-representante da Juventude Terena, para o III Encontro da Juventude Terena, na aldeia Cachoeirinha, no Município de Miranda. Durante o evento conheci jovens indígenas de várias aldeias Terena do Estado. Ao participar de um dos grupos de trabalho, fiquei impressionada pelas percepções, apresentadas pelos jovens Terena presentes no encontro, sobre questões territoriais, sustentabilidade, saúde e principalmente educação.

Nesse sentido acreditamos ser relevante o estudo das práticas realizadas pelos jovens Terena na construção do protagonismo juvenil e participação no Movimento Indígena. Os dados estão sendo acumulados desde 2015 junto a Comissão da Juventude Terena, além de reuniões, seminários e atividades desenvolvidas em torno da Grande Assembleia do Povo Terena. Essas experiências estão permitindo uma reflexão sobre o processo de articulação da juventude Terena, bem como os dilemas e dificuldades enfrentados por essa categoria. É sob essa perspectiva que se desenvolve este artigo, entretanto, as possibilidades analíticas e explicativas sobre o objeto de pesquisa não se esgotam aqui. 
Os Terena constituem a segunda maior população indígena de Mato Grosso do Sul. São estimados cerca de 26.065 indivíduos (Siasi/Sesai, 2014). Vivem em sete reservas indígenas, criadas pelo processo de colonização, e que hoje se encontram em processo de demarcação. São elas, T.I Buriti, em Dois Irmãos do Buriti e Sidrolândia, T.I Nioaque, em Nioaque, T.I. Limão Verde, T.I. Taunay-Ipegue, em Aquidauana T.I. Lalima, T.I. Pillad Rebuá e T.I. Cachoeirinha, em Miranda. Temos também a presença de famílias Terena vivendo em Porto Murtinho na T.I Kadiwéu, em Dourados na reserva Jaguapiru e Bororó, em aldeias urbanas de Campo Grande (Água Branca, Marçal de Souza, Tarsila do Amaral, Comunidade Indígena do Núcleo Industrial e Darci Ribeiro), e em mais duas TIs (Araribá e Icatu), juntamente com outras etnias no Estado de São Paulo. E, há aproximadamente 20 anos, um grupo se deslocou da TI Buriti, para o Estado de Mato Grosso onde hoje ocupam a TI Terena Gleba Iriri, no norte do Estado (SANT'ANA, 2009).

Os Terena também iniciaram um processo chamado de "retomadas" de território, devido a lentidão e falta de resposta por parte do Estado brasileiro às suas reivindicações de demarcação dos territórios tradicionais. Hoje são cerca de vinte e duas áreas retomadas. As áreas retomadas na região de Miranda foram: fazenda Charqueado do Agaxi, Santa Vitória, Trator Mil, Boa Esperança e Paratudal. Já as áreas retomadas na região de Aquidauana são: Fazenda Caçula, Touro, Esperança, Fazendinha, Funil, Cristalina, Persistência, Cedral, Capão da Arara, Boi Preto, Ouro Preto, Nova Bahia, Ipanema e Maria do Carmo. Na região de Sidrolândia e Dois Irmãos do Buriti foram mais de 29 fazendas retomadas, totalizando cerca de 11 mil hectares. Além dessas áreas, temos a Aldeia Aldeinha, ocupação indígena, no Município de Anastácio, Aldeia Tico Lipú, ocupação indígena, em Aquidauana, Aldeia Tereré, ocupação indígena, em Sidrolândia, e as mais recentes, ocupação Santa Mônica, Romana e ‘Tumunemó Kalivonó’ em Campo Grande somando assim onze aldeias urbanas no Estado.

O Mato Grosso do Sul, é entre as unidades da federação, que mais apresenta casos de violência contra os povos indígenas no país. O Estado também, foi uma das áreas que mais registraram casos de suicídios indígenas em 2016, além dos inúmeros processos demarcatórios paralisados na justiça (CIMI, 2017).

É nesse cenário, então, que se insere a juventude Terena. Grande parte dessa população vive em suas terras originárias, outra vive nos centros urbanos por terem a sustentabilidade em seus territórios violados por fatores externos. Muitos fatores influenciam na qualidade de vida, e no acesso a direitos que tornam o jovem consciente do seu papel transformador e regulador da própria vida e das relações de convívio que o cercam. 
Nesse sentido o Encontro da Juventude Terena tem como objetivo unir forças em torno do bem viver das comunidades indígenas, é um espaço para a juventude se expressar e se reconhecer, sobretudo é um movimento aliado das lideranças indígenas de vanguarda, que sempre estiveram na linha de frente da luta.

A juventude Terena tem fortalecido sua organização através da "Grande Assembleia do Povo Terena", de maneira que além de acompanhar, os jovens tem encarado o desafio de fazer juntos com as lideranças a gestão dos territórios e garantir os direitos indígenas duramente conquistados na Constituição Federal de 1988.

\section{Assembleia do Povo Terena}

A partir da década de 1980, o Brasil passou por um processo de redemocratização, o que veio favorecer a entrada de temas levantados e inseridos na agenda nacional através dos povos indígenas, que variaram em: reconhecimento dos direitos dos povos indígenas, enquanto povo, a questão da demarcação das terras tradicionais, a saúde, a educação entre outros.

Nesse sentido, Baltazar (2013), explica que:

[...] o protagonismo indígena no Brasil começava a se manifestar com maior intensidade nos anos 70 a partir das assembleias indígenas regionais e nacionais apoiadas pelo CIMI (Conselho Indigenista Missionário). Pela primeira vez reuniamse as lideranças indígenas de diferentes povos do Brasil com trocas de informações sobre o contexto de enfrentamento e de experiência dos problemas vividos. Surgia também a o senso de solidariedade das lideranças indígenas constituindo a união e espírito corporativo entre povos que serviu de base para as futuras mobilizações indígenas (p.268).

Desde então, se deram as articulações entre os povos na organização e mobilização em busca por parceiros para apoio a luta e até mesmo apoio internacional, para exigir do estado Brasileiro o reconhecimento e a garantia dos direitos. Os anos de descaso e omissão por parte do Estado serviram para que os povos indígenas tivessem uma reação e caminhassem para o enfrentamento, com bastante organização e articulação de debates nas assembleias indígenas, local de grito e resistência.

\section{1 "Ressurgimento" da Assembleia do Povo Terena: O Conselho Terena}

Os Terena após a Guerra do Paraguai se mantiveram focalizados na organização interna local, deixando a antiga organização regional inutilizada. Cada cacique se concentrou mais em cuidar da organização interna da comunidade e no âmbito municipal. 
Todavia, a vontade de ver seu território demarcado definitivamente e a morosidade do estado em dar respostas ágeis e satisfatórias às reivindicações, forçou, de maneira natural, a revitalização do movimento regional dos Terena e a partir de 2012, nos meses de fevereiro a abril, as lideranças realizaram reuniões semanais em várias comunidades Terena da Terra Indígena Taunay/Ipegue, município de Aquidauana, MS (Aldeia Bananal, Aldeia Morrinho e Aldeia Água Branca), para obterem esclarecimentos e informações sobre a situação jurídicopolítica das T.I's, despertando nas lideranças ativas participantes a necessidade de reconstituir a Grande Assembleia do Povo Terena e o funilamento de representatividade através do Conselho do Povo Terena. Esses encontros foram reuniões preparatórias, visto que as lideranças estavam dispersas e não havia uma comunhão única de forças voltadas para a luta pela terra.

O Conselho do Povo Terena é formado pelas lideranças indígenas, mulheres, rezadores, professores indígenas e juventude terena.

Essas reuniões culminaram com a realização da $1^{\text {a }}$ Assembleia Terena (Hánaiti Ho'únevo Têrenoe) que foi realizado na Aldeia Imbirussú, na terra indígena Taunay/Ipegue, que contou com a participação de caciques terena, lideranças do povo Kinikinau e Kadiwéu. O documento final da primeira assembleia pontua que foi a primeira vez, desde a guerra do Paraguai que os povos indígenas do pantanal se reuniram novamente.

A participação política de lideranças indígenas Terena vai conduzir a existência de um novo espaço político no Estado de Mato Grosso do Sul, no âmbito de uma satisfação das necessidades das comunidades, interferindo nos rumos da sociedade mato-grossense-do-sul.

A Assembleia do Povo Terena se configura em um espaço político de articulação e tomada de decisões importantes para o grupo. São grandes reuniões que contam com a participação de lideranças indígenas do estado e nacionais, além de representantes de órgãos governamentais e não governamentais. Ocorrem anualmente, podendo haver convocatória antes desse prazo, a depender das precisões do movimento. A exemplo, de 07 a 10 de Maio de 2014, na aldeia Babaçu, município de Miranda, aconteceu uma assembleia extraordinária, a última havia sido realizada de 13 a 16 de novembro de 2013, na aldeia Brejão, município de Nioaque. Dois motivos foram decisivos para a realização da assembleia extraordinária: as eleições de 2014 e a tentativa do poder legislativo de aprovar a PEC 215, a qual transferiria da Presidência da República para o congresso nacional a palavra final sobre a demarcação das terras indígenas. 
Durante esses eventos que marcam a organização Terena, evidencia-se a ótica das lideranças indígenas Terena sobre a recuperação dos territórios tradicionais, a reposição dos recursos naturais, a proposta de desenvolvimento segundo a lógica indígena, a construção de uma escola diferenciada, saúde indígena, educação superior indígena, pós-graduação entre tantos outros temas (VIEIRA,2013).

Essas associações indígenas são importantes direcionadoras, executoras, gestoras de políticas que antes eram administradas pelo estado. Essas atividades acontecem sob forma de projetos e são desenvolvidos nas mais diversas áreas (cultura, educação, gestão ambiental) e imersas a uma estrutura burocrática.

O povo Terena nos últimos quatro anos está vivendo um estágio de profunda reivindicação de direitos territoriais. Em 2013, com a organização sistemática de duas grandes reuniões anuais (Assembleia Terena) vários foram os movimentos tanto a nível estadual quanto nacional das lideranças Terena para a defesa de seus direitos conquistados na Constituição de 1988. Essas mobilizações estão articuladas com o movimento indígena a nível nacional (APIB) e tem contado com a participação de lideranças de outras regiões do país que estão na luta por territórios tradicionais (Babau Tupinambá, Nailton Pataxó, Sônia Guajajara, Júnior Xucurú, Geovani Krenak, Kretã Kaingang, entre outros). Como parte deste processo de luta as grandes assembleias tem contribuído de modo a organizar a luta e formas de estratégias de enfrentamento as violação de direitos.

\section{Encontro da Juventude Terena}

O I Encontro da Juventude Terena, nasceu do bojo da discussão na “Hánaiti Ho' Únevo Têrenoe" (Grande Assembleia do Povo Terena), realizada na Aldeia Imbirissú, em junho de 2012.

Nos dias 27, 28 e 29 de julho de 2012, reuniram-se, na Aldeia Bananal, na T.I. Taunay/ Ipegue, a Juventude Terena, com representantes da Aldeia Bananal, Ipegue, Água Branca, Lagoinha, Passarinho, Lalima, Cachoeirinha, Mãe Terra, Buriti, juntamente com representantes do Povo Kadiwéu e Conselho Aty Guasu Jovens - Guarani e Kaiowá, lideranças, anciões, professores e comunidade, para refletir sobre o "Despertar da Juventude Terena" (Iyúkeovohiko Isóneuhiko Kali Kopénotihiko Têrenoe). A Comissão da Juventude Terena é composta por estudantes/juventude, professores e lideranças Terena. E nesse intuito soma com o Movimento Indígena na luta pelos seus direitos. Tendo por objetivo sempre defender os princípios do bem viver de suas comunidades. 
Entre os dias 19 a 22 de outubro de 2017, foi realizado a V Assembleia da Juventude Terena, na Aldeia Cabeceira, Terra Indígena Nioaque, município de Nioaque, Estado do Mato Grosso do Sul, se fizeram presentes a juventude das Aldeias La Lima, Cachoeirinha, Mãe Terra do município de Miranda-MS, Aldeia Aldeinha, do município de Anastácio-MS, Aldeia Limão Verde e Aldeia Ipegue, do município de Aquidauana-MS, Aldeia Buriti do município de Dois Irmãos do Buriti, Aldeia Tereré do município de Sidrolândia-MS. Também se fizeram presentes neste Encontro jovens representantes da juventude Xavante, Kadiwéu, Kinikinau, Atikum, Guarani e Kaiowá e do Movimento dos Trabalhadores Sem Terra -MST. Além da juventude indígena, também teve a presença de anciões, professores e professoras, caciques e lideranças do Conselho do Povo Terena, do Conselho Kinikinau e do Conselho Aty Guasu, somando mais de 400 participantes.

\section{1 "Falam que somos o futuro, mas digo que somos o presente!"}

Essa foi uma fala expressiva do representante estadual da Juventude Terena, Reinaldo Souza, durante o V Encontro da Juventude Terena. Morador da aldeia Lalima, T.I. Lalima, no Município de Miranda, Reinaldo foi escolhido para ser representante da Juventude Terena, durante o II Encontro da Juventude Terena, realizado em sua aldeia natal. Desde então, vem participando de eventos municipais, estaduais e nacionais de políticas para a juventude. Ele é também representante da juventude indígena do Centro-Oeste, juntamente com Beto Xavante, na Comissão Nacional da Juventude (CONJUVE).

Para ele a juventude não pode esperar o futuro para agir: "nossos líderes e anciões esperam e apostam em nós, somos realidade, somos os futuros líderes de nossas comunidades, por isso temos que lutar desde agora com as lideranças tradicionais, caciques e conselhos tribais de nossas comunidades, temos que pegar experiência, e aprender a ser sábios". Além disso, acredita que o Encontro da Juventude Terena é um momento importante que fornece muitas informações sobre os direitos indígenas, fazendo a juventude "despertar" para aquilo que lhe é de direito.

Segundo uma acadêmica indígena, o Encontro da Juventude Terena é um momento importante para trocas de experiências que cada jovem Terena tem ao ir para cidade, especificamente quando estes ingressam no terceiro grau e um momento para dialogar com outros acadêmicos indígenas sobre a maneira que poderão contribuir com suas comunidades depois de formados. "Não é fácil você sair da sua aldeia, você enfrenta muitas dificuldades, você precisa seguir o ritmo de um novo lugar, de novas pessoas. Aqui nós podemos falar 
sobre nossas dificuldades, aqui a gente pode pensar junto em como enfrentar essas dificuldades. As vezes o que eu passo, o outro parente também passa, então dá para pensar junto".

Para Alessandro Miranda, representante da Juventude Indígena da T.I. Nioaque, a interação entre os jovens contribui para a compreensão do que é o Movimento Indígena e fornece informações sobre a situação que se encontra as terras indígenas do Estado. " $\mathrm{O}$ Encontro faz com que a juventude dialogue, interaja, isso é positivo pois um vai explicando para o outro o que é o Movimento Indígena e abre as mentes principalmente na questão da recuperação de nossas terras".

Segundo uma jovem Terena da aldeia Limão Verde, o Encontro aproxima a juventude dos anciãos, os quais são guardiões da cultura e saberes indígenas, tão necessários para não esquecermos de nossas origens e de nossas comunidades. "Gosto do encontro por que ele traz também os nossos livros vivos, os nossos anciões. Eles ensinam como devemos agir, fico triste por que eles falam nossa língua e nós juventude... precisamos recuperar nossa língua, e só através deles, eles nos dão força e mostram nossas raízes", enfatizou.

Além do Encontro anual, o Conselho da Juventude busca estabelecer uma rede de comunicação permanente entre a juventude através das redes sociais e outros meios de comunicação virtual. Apesar da distância geográfica, os membros do Conselho da Juventude Terena vem construindo suas agendas e atividades através desses meios, bem como socializando informações que buscam fortalecer o grupo.

O objetivo geral da Assembleia da Juventude Terena foi a discussão dos Direitos Indígenas, a Luta e o Protagonismo Juvenil, portanto, os debates giraram em torno das dificuldades encontradas pela juventude indígena nas diferentes áreas, sejam elas, na educação, na saúde, na segurança, nas políticas públicas e também na demarcação das terras indígenas.

O evento foi organizado em Temáticas, em seguida eram realizadas rodas de conversa. A principal função das rodas de conversas era aproximar a juventude para que pudessem se conhecer e discutir os desafios e as ameaças aos direitos indígenas. Em seguida, foi apresentada uma diversidade de propostas, de maneira que foi necessário unificá-las. Todos e todas puderam expor suas opiniões e apresentar suas demandas. No final do evento foi feito um documento final, de maneira que a mesma será integrada as do Conselho do Povo Terena e direcionada aos órgãos competentes. 
A juventude Terena firmou o compromisso de continuar lutando, em sintonia com o Movimento Indígena nacional, contra todos os retrocessos de direitos, reafirmaram também o compromisso de integrar Articulação dos Povos Indígenas do Brasil - APIB, juntamente com as demais organizações de base do Movimento Indígena.

Neste sentido, a Assembleia da Juventude Terena do Estado do Mato Grosso do Sul expôs a público os seguintes encaminhamentos:

1 - Tendo em vista o grave retrocesso sofrido pelas comunidades indígenas, com a paralisação na demarcação dos territórios indígenas em todo o Brasil, esta assembleia exige do Governo Federal a imediata demarcação de nossas terras ancestralmente ocupadas, conforme prevê a Constituição Federal;

2 - Repudiamos e afirmamos nosso compromisso em combater o avanço dos setores antiíndígenas, de nível nacional, que a cada dia propõem e impulsionam medidas que visam, exclusivamente, a retirada dos direitos indígenas ancorados na Constituição Federal de 1988;

3 - Repudiamos, veementemente, a tese ruralista, do Marco Temporal como critério para demarcação de Terras Indígenas no Brasil, por tratar-se de mais uma medida inconstitucional que despreza o direito e a história do Povo Indígena do Brasil;

4 - Repudiamos também a proposta do Governo ilegítimo e golpista de autorizar o arrendamento de terras indígenas em nosso país, pois sabemos que essa medida visa tão somente a livre exploração de nossos territórios ancestrais, causando a desterritorialização de nossas áreas já demarcadas e em demarcação, devemos ainda dizer que a Constituição Federal não permite tal medida e nos, povos indígenas, temos o direito a colocar em prática nossos projetos societários.

5 - Diante da situação de grave descaso em relação ao atendimento na saúde indígena pela Secretária Especial de Saúde, esta assembleia exige o aperfeiçoamento do atendimento à saúde, e ressaltamos a necessidade de criação de programas dentro da SESAI para atendimento em relação a prevenção de doenças sexualmente transmissíveis, gravidez na adolescência, consumo de drogas nas comunidades indígenas; Frisamos ainda, a importância do resgate e da preservação da alimentação tradicional, reforçando que a alimentação ocidental com alto consumo de alimentos industrializados, como refrigerante, bolachas recheadas, doces e alimentos com auto teor de gordura, causam o aumento de doenças crônicas não transmissíveis, como a hipertensão arterial e o diabetes Mellitus; 
6 - A juventude Guarani e Kaiowá presentes na assembleia da juventude Terena exigem a melhoria no atendimento à saúde indígena no Cone Sul do estado, especificamente, no que toca a saúde mental em áreas de retomada e em áreas de aldeia atual(reservas);

7 - Esta assembleia apoia a imediata efetivação da Portaria 628 que dispõe sobre as especificidades no atendimento ao indígena pelo sistema público de saúde, inclusive, ressaltase, a necessidade de intérprete da língua materna em todos os hospitais públicos do estado, conforme prevê a portaria citada;

8 - Esta assembleia repudia a nomeação a cargo de coordenação que são indicados sem prévia consulta as comunidades indígenas;

9 - Garantir a contratação de profissionais indígenas para prestação de serviço junto as comunidades indígenas;

10 - Esta assembleia exige o fortalecimento da Educação Escolar Indígena, a partir do sistema colaborativo (esfera municipal, estadual e federal), com base na Constituição Federal de 1988, no Artigo 231 e no Artigo 210, na Lei de Diretrizes e Bases da Educação, Lei n 9394, de 1996 e Decreto 6861/2009 dos Territórios Etnoeducacionais. Ressaltamos como pontos importantes para efetivação de uma Educação Escolar específica e diferenciada, imediato atendimento e garantia da educação escolar nas áreas de retomada, a realização de concurso específico para profissionais indígenas aos cargos da educação, a construção de salas de aula nas aldeias de maior necessidade; a instituição do sistema de cotas nos cursos de pósgraduação das universidades, Estadual e Federal ,do Estado, bem como a garantia de políticas de permanência;

Por fim, nossa assembleia, ovacionadamente, elegeu a comunidade da Aldeia Limão Verde para sediar a V Assembleia da Juventude Terena em setembro de 2018.

Continuaremos defendendo o fortalecimento do órgão indigenista oficial do estado brasileiro a FUNAI, que neste momento está sofrendo ataques e encontra-se nas mãos de setores antiíndígenas.

Ressaltamos também que não reconhecemos o governo ilegítimo e golpista que vem retirando direitos da classe pobre deste país, atacando diariamente os direitos dos povos indígenas, colocando-os como moeda de troca por apoio contra as graves denúncias que surgem contra esse governo.

Afirmamos que não permitiremos que nossos direitos consagrados na Constituição Federal não serão retirados de lá, sem que nosso povo lute até o último instante para mantêlos e efetivá-los. 


\section{Considerações Finais}

O Encontro da Juventude Terena tem se constituído em uma importante mobilização e articulação da juventude indígena Terena para formação em temas relacionados aos direitos indígenas, conquistados pelo Movimento Indígena (CF 88, Convenção 169 da OIT, política de saúde, política de gestão territorial, política de educação, entre outras).

Ficou evidenciado a preocupação e interesse da juventude que no Encontro se formem multiplicadores de ideias, de maneira que tudo que foi trabalhado durante o evento, possa ser transmitido para o maior número de pessoas dentro das comunidades indígenas. Como estratégia, houve a reorganização do Conselho da Juventude Terena e o acréscimo de novos jovens no grupo. Os novos integrantes terão como missão fazer o intermédio entre Conselho e comunidades indígenas, criando assim um meio de trocas de experiências, socializações e construção do próximo Encontro.

Uma das maiores expressões de luta da juventude Terena é "queremos lutar junto com nossas lideranças, queremos nossos direitos e só vamos conseguir lutando", segundo a vicerepresentante da juventude Terena, Edna, moradora da aldeia Cabeceira, T.I. Nioaque. Durante a Grande Assembleia do Povo Terena, há um espaço para apresentação das pautas relacionadas a juventude indígena, momento oportuno para fortalecimento do compromisso da juventude indígena com a história de luta de suas lideranças e com suas comunidades.

Para Dercy Viana, jovem Guarani, o Encontro demonstra que o a luta dos povos indígenas é mais forte por meio da união dos povos e fica evidenciada a confiança das lideranças nos jovens, de maneira que os primeiros transmitem seus conhecimentos para que a juventude possa ser forte e sábia em qualquer ambiente.

Acreditamos que o Encontro da Juventude Terena vem para informar, interagir e difundir a importância do território na implementação de políticas públicas e de valorização dos espaços locais, da identidade étnica, além de intensificar o diálogo entre a juventude, a qual passa a identificar os principais dilemas que causam o preconceito, a desigualdade social e a desterritorialização dos povos indígenas. Ainda, incentiva novas práticas de vivenciar as adversidades reservadas as populações indígenas. O foco do encontro são os jovens, enquanto sujeitos de direitos, capazes de agir localmente, valorizando sua cultura, desenvolvendo novas práticas e posturas diante dos enfrentamentos que a sociedade nacional os coloca.

\section{Referências}


CARDOSO DE OLIVEIRA, Roberto. A Sociologia do Brasil Indígena. Rio de Janeiro: Tempo Brasileiro, 1978.

CARDOSO DE OLIVEIRA, Roberto. Do Índio ao Bugre: o processo de assimilação dos Terena. Rio de Janeiro: F. Alves, 1976.

CARDOSO DE OLIVEIRA, Roberto. O Índio e o Mundo dos Brancos. 3 ed. Brasília: Editora de Brasília; São Paulo: Pioneira, 1981.

CARDOSO DE OLIVEIRA, Roberto. Urbanização e Tribalismo: a integração dos índios Terena numa sociedade de classes. Rio de Janeiro: Zahar Editora, 1968.

URQUIZA,A.H.A.(Org.). Culturas e História dos Povos Indígenas em Mato Grosso do Sul. Campo Grande: Ed. UFMS, 2013.

DE PAULA, Luís Roberto; VIANNA, Fernando Luiz Brito. Mapeando Políticas Públicas para Povos Indígenas. Rio de Janeiro: Contra Capa Livraria; LACED/MUSEU NACIONAL/UFRJ, 2011.

MINDLIN, Betty; PAITER, Suni. Vozes da Origem. Rio de Janeiro/São Paulo: Editora Record, 2007.

GUTIERREZ, J.P. e URQUIZA, A.H.A.(Org.). Direitos Humanos e Cidadania: desenvolvimento pela educação em Direitos Humanos. Campo Grande: Ed. UFMS, 2013. 